Royal Society and in 1766 received the Copley Medal for his "Experiments on the Specific Gravities of the Several Metals". Afterwards he was much concerned in the lightning conductor controversy. Dr. Charles Hutton (1737-1823), the son of a Newcastle colliery worker, started with little education, but rose to be the professor of mathematics at the Royal Military Academy, Woolwich. He was the leading authority on gunnery, and a notable figure in the Royal Society. $\mathrm{He}$ retired in 1807 and was succeeded by Olinthus Gregory, but he lived another sixteen years. At his death he was buried at Charlton, Kent. His bust he bequeathed to the Newcastle upon Tyne Literary and Philosophical Society, which had been founded in 1793. Dr. George Peacock (1791-1858), of Thornton Hall, Denton, in Durham, another mathematician, belonged to a later generation. Entering Cambridge at the age of eighteen, he assisted in founding the Analytical Society, which, for the benefit of students, published a translation of the "Differential Calculus" of Lacroix. A man of great charm, in 1836 he became Lowndean professor of astronomy, and three years later also Dean of Ely, where he is buried. At his death, Airy wrote to his widow : "All my debts to other friends in the University added together are not comparable to what I owe to the late Dean ....". Airy himself had associations with the North, for he was born at Alnwick, where his father was an excise officer.

Whatever interest, however, may be felt in the careers of these and other men of science, for many, the history of Durham and Northumberland is associated with their collieries, railroads, locomotives and ships. Of the leading pioneers of the locomotive, Matthew Murray (1765-1826) of Leeds, William Hedley (1779-1843), John Urpeth Rastrick (1780-1856), George Stephenson (1781-1848), Timothy Hackworth (1786-1850), Robert Stephenson (180359), and Sir Daniel Gooch (1816-89) were all born on the banks of the Tyne, and the construction of their historic locomotives "Puffing Billy", "Wylam Willy", "Blucher", "Locomotion" and "Rocket", of the Stockton and Darlington Railway, as also of the Liverpool and Manchester Railway, are landmarks in the history of land transport. There are many monuments to these north-country pioneers, and as recently as 1947 a tablet was placed on Hackworth's house at New Shildon, Durham, while two years later, through the action of the North-East Coast Institution of Engineers and Shipbuilders, the cottage at Wylam in which George Stephenson was born was transferred to the custody of the National Trust.

\section{I POPULATION CENSUS OF ENGLAND AND WALES}

$\mathrm{T}$ HE detailed results of the fifteenth Census of Population of England and Wales, taken on April 8, 1951, will be eagerly awaited, as it is twenty years since the last census was taken, 1941 being the first break in the regular series of decennial censuses dating from 1801. It is, however, forty years since there last was a simultaneous count of the population of all the constituent areas of the United Kingdom and the Irish Republic. In 1951 the Census authorities of England and Wales, Scotland, Northern Ireland, the Channel Islands, the Isle of Man and the Irish Republic acted in concert, and a Census was taken on the same day in all these territories. It is to be hoped that this arrangement will continue in future, as the volume of migration between different parts of the British Isles is not inconsiderable and the territorial units which are of interest to students of population are generally larger than the unit covered by one Census authority. It would be of great assistance if definitions and tables in the full reports could be standardized, and summary tables relating to Great Britain, the United Kingdom, and the British Isles as a whole published.

A full appreciation of the results of the Census, which contained a number of new questions asked for the first time on this occasion, will have to await the publication of the detailed reports. The time-lag between Census day and publication will, however, be considerably shortened in England and Wales, for the Registrar General proposes to analyse a sample of 1 per cent of the Census schedules and to publish main tabulations relating to this sample within a year of enumeration.

The preliminary report*, which has recently been published, is, as is customary, based not on an analysis of the actual Census schedules but on a count made from summaries supplied by the local Census officers. Its purpose is restricted, and its main function is to give provisional figures for the total population, classified by sex, of all local-government areas in the country down to district level. For the social scientist its main importance lies in the information it gives on total numbers and on the geographical distribution of the population.

Table 1. 'Total Popula'tions and Rates of Change in the british ISLES, $1921-51$

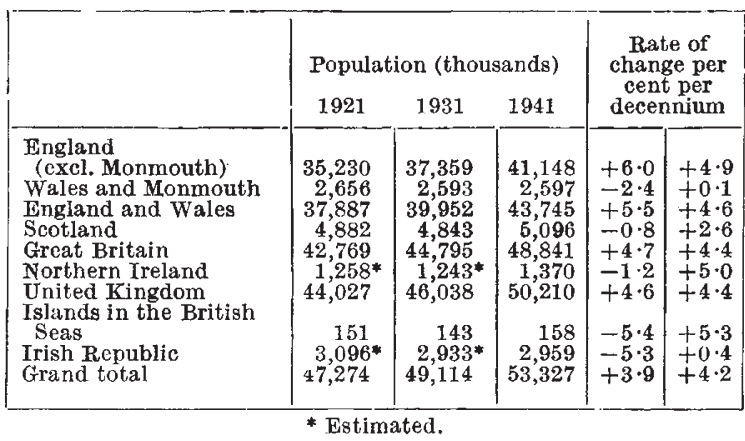

The total populations of the different constituent parts of the British Isles are shown in Table 1, together with their rates of change. To make for easier com. parability the rates of change for the twenty years 1931-51 have been converted to average rates for decennia. The table shows that for the British Isles as a whole the population increased at a slightly higher rate between 1931 and 1951 than during the decennium 1921-31. In the United Kingdom, however, the rate of increase remained practically stationary at $4 \frac{1}{2}$ per cent for ten years. Within the United Kingdom, Wales, Scotland and Northern Ireland increased in population during 1931-51 after registering a decline in total numbers during 1921-31. This decline, however, was probably due to a negative balance of migration.

Confining our attention to England and Wales, two features of interest must be pointed out. In the first place, for the first time in the past century there has been a net gain of population due to migration. This

* General Register Office. Census 1951, England and Wales. Preliminary Report. Pp. xxiii + 52. (London: H.M. Stationery Office, 
gain is estimated at about half a million for the period 1931-51. It is due to the return of British subjects resident abroad, the demobilization of Allied and Dominion soldiers in Britain, and to a small part to the immigration of refugees and displaced persons. 'The net balance of migration from other parts of the United Kingdom can only be estimated since the introduction of the National Register in 1939, and it is believed that this factor accounts for an increase of between 250,000 and 300,000 since that time.

The second feature that needs comment is that the decennial rate of increase is the lowest ever recorded, in spite of the net gain from migration to which reference has already been made. It is true that since 1931 there have occurred 360,000 deaths, estimated as being due to the War. But the losses of the First World War were much heavier, both absolutely and relatively, than those of the Second, and yet the rate of increase between 1911 and 1921 amounted to 4.9 per cent in spite of a net outward balance of migration. It is therefore difficult to accept the statement in the text that "there is no sign of any tapering away of the successive increments such as would normally be expected to herald the early approach of an ultimate population maximum". The Registrar General's technical advisers must be aware that figures of total population cannot provide any reliable guide to prospects of future development of population, and it would have been wiser to wait for the more detailed information on age distribution and fertility before committing oneself to this view on the future. Taking recent registration figures into account, it would be very surprising if the rate of increase between the present Census and the next will not be substantially lower than $4 \frac{1}{2}$ per cent per decennium.

The overall rate of increase for the country as a whole masks considerable variations in the rate of increase for different regions. The geographical distribution of the population has changed since 1931, and the proportionate importance and rates of increase of the different standard regions are shown in Table 2. It is clear from this table that the eastern and southern regions of the country continue to grow at the expense of the north and the north-west. But a new tendency has become evident since 1931. The rate of increase of London and the south-east, which was well above the national average during the previous decennium, has fallen spectacularly and the proportionate importance of that region has decreased. Conversely, the rates of increase of the Midland and south-western region have shot up. It will be interesting to analyse the changes in age, occupational and industrial distribution of the populations of

'lable 2. Proportionate Populations in DifHerent Regions of

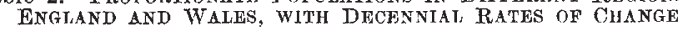

\begin{tabular}{|c|c|c|c|c|c|}
\hline \multirow[t]{2}{*}{ Region } & \multicolumn{3}{|c|}{$\begin{array}{l}\text { Population per cent } \\
\text { total }\end{array}$} & \multicolumn{2}{|c|}{$\begin{array}{l}\text { Rate of change } \\
\text { per decennium }\end{array}$} \\
\hline & 1921 & 1931 & 1951 & $1921 / 31$ & $1931 / 51$ \\
\hline Eastern & $5 \cdot 8$ & $6 \cdot 1$ & $7 \cdot 1$ & $+11 \cdot 5$ & $+12 \cdot 8$ \\
\hline Southern & $5 \cdot 1$ & $5 \cdot 3$ & $6 \cdot 1$ & $+11 \cdot 3$ & +11.4 \\
\hline Midland & $9 \cdot 4$ & $9 \cdot 4$ & $10 \cdot 1$ & $+5 \cdot 6$ & $+8 \cdot 7$ \\
\hline South-w estern & $6 \cdot 6$ & $6 \cdot 5$ & $6 \cdot 9$ & $+4 \cdot 1$ & $+7 \cdot 5$ \\
\hline North Midland & $7 \cdot 3$ & $7 \cdot 4$ & $7 \cdot 7$ & $+6 \cdot 4$ & $+7 \cdot 2$ \\
\hline $\begin{array}{l}\text { London and south- } \\
\text { east }\end{array}$ & $25 \cdot 0$ & $25 \cdot 9$ & $24 \cdot 9$ & $+9 \cdot 2$ & $+2 \cdot 7$ \\
\hline $\begin{array}{l}\text { East and West } \\
\text { Riding }\end{array}$ & $9 \cdot 9$ & $9 \cdot 8$ & $9 \cdot 4$ & $+4 \cdot 4$ & $+2 \cdot 1$ \\
\hline North-western & $16 \cdot 0$ & $15 \cdot 5$ & $14 \cdot 7$ & $+4 \cdot 0$ & $+2 \cdot 0$ \\
\hline Northern & $8 \cdot 0$ & $7 \cdot 6$ & $7 \cdot 2$ & +0.8 & $+1 \cdot 6$ \\
\hline Wales & $7 \cdot 0$ & $6 \cdot 5$ & $5 \cdot \overline{9}$ & $-2 \cdot 4$ & +0.0 \\
\hline England and Wales & $100 \cdot 0$ & $100 \cdot 0$ & $100 \cdot 0$ & $+5 \cdot 5$ & $+4 \cdot 6$ \\
\hline
\end{tabular}

those regions, but this will not be possible until the detailed tables are published.

Some comments have been made on the change in the proportion of the urban population. It appears as though the percentage classified as urban has decreased slightly since 1931. The report shows that this decrease took place almost entirely after 1939 . But, again, the figures must be interpreted with caution. There have been no changes in localgovernment boundaries since 1939, and it is possible that the slight increase in the rural population is merely a reflexion of the increasing tendency of city dwellers to move to the peripheral suburbs, some of which may be classed as rural districts. A detailed study of this question will have to await the publication of the report on place of residence and place of work.

The above remarks make it clear that only very provisional conclusions can be drawn from the preliminary report. New light will be thrown on many problems, however, when the final volumes begin to come out. The abnormally long interval between the past two censuses has been a great obstacle in the way of those who are interested in local or regional studies. It is to be hoped that there will never again be so long an interval between two censuses. Provision was made in the Census Act of 1920 for a census to be taken not more frequently than once every five years, and it is to be hoped that the provisions of the Act will be usəd and a new census taken in 1956 .

E. Grebenik

\section{SOME EXPERIMENTAL WNORK CARRIED OUT IN PHYSICS WITH THE LARGER HARWELL PILE}

WIS article describes a few of the experiments which have been carried out in physics at Harwell with the larger atomic-energy pile known as BEPO.

\section{Neutron Crystallography}

A double-crystal neutron spectrometer, which utilizes a collimated beam of thermal neutrons from the therinal column, has been designed and made for work on neutron crystallography ${ }^{1}$, and has been used, among other things, for checking theoretical predictions regarding the intensity of reflexion of monochromatic neutrons from single crystals, with a view to the ultimate use of such crystals in structure analysis. The use of single crystals is elearly desirable if adequate progress is to be made in neutron crystallography, but has been restricted by the appreciable extinction effects arising from the large crystals that have hitherto been employed. From a series of intensity measurements, made under carefully controlled conditions, it has been found that the theoretical intensity relationships worked out by Bacon and Thewlis ${ }^{2}$, and Bacon and Lowde ${ }^{3}$, according to which the integrated intensity of reflexion is dependent, for thick crystals, not on the structure factor but largely on the degree of mosaic spread, are in fact valid; further study ${ }^{4}$, however, has led to the discovery that relatively large crystals can be used if they are of the right shape. For potassium bromide, a crystal typical of many in this field, a specimen $1 \mathrm{~cm}$. long and $2 \mathrm{~mm}$. square in crosssection, permits the proportionality between integrated intensity and structure factor to be retained. 